\title{
PROCEDIMENTO DIDÁTICO PARA DIMENSIONAMENTO DE TROCADOR DE CALOR COMPACTO TIPO COIL
}

DOI: 10.37702/2175-957X.COBENGE.2021.3463

Carlos Henrique de Paula Junior - chpj_1993@hotmail.com

Universidade do Estado do Rio de Janeiro

Rua Doutor Geraldo de Carvalho , numero 78 apartamento 302 , interfone 20278

27541-250 - Resende - RJ

Luiz Carlos Cordeiro Jr - luiz.cordeiro@fat.uerj.br

UERJ

Rua Benedito Alves de Moraes 157

27523-116 - Resende - RJ

Gabriel Oliveira Lara Rosa - gabrielolrosa@gmail.com

Universidade do Estado do Rio de Janeiro

Rua Cel. José Pessoa 125

27542-050 - Resende - RJ

Jônatas Durante Lopes - jonatasdlopes97@gmail.com

Universidade do Estado do Rio de Janeiro

Rua João Ourique Ferreira - Alambari 11

27534-120 - Resende - RJ

Resumo: $O$ trabalho em questão tem como objetivo realizar análise térmica em trocador de calor do tipo "coil", utilizado em sistema de freio pneumático veicular. Para esta análise, o mapeamento térmico foi desenvolvido através de simulação veicular nas condições estática e dinâmica, dentro das instalações do Laboratório de Mecânica/UERJ/Campos Regional de Resende. O resultado deste trabalho serviu para auxiliar na compreensão do dimensionamento, da aplicação deste trocador de calor e da influência dos efeitos geométricos na sua construção para troca térmica culminando no desenvolvimento de aulas experimentais na disciplina de Fenômenos de Transporte Experimental para o curso de Engenharia Mecânica por meio da criação de uma bancada de baixo custo, a fim de proporcionar aos alunos inovação nas propostas pedagógicas da matéria e de outras matérias correlatas.

Palavras-chave: trocador de calor tipo coil, coil designer, sistema de freio 


\section{(C. COBENGE e IV Simpósio Internacional de Educação em Engenharia

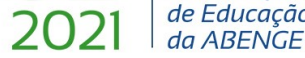 28 a 30 de SETEMBRO

veicular e bancada didática. 


\section{PROCEDIMENTO DIDÁTICO PARA DIMENSIONAMENTO DE TROCADOR DE CALOR COMPACTO TIPO COIL}

\section{INTRODUÇÃO}

Dentro da área da engenharia térmica, os trocadores de calor são de grande importância no desenvolvimento de estudos e pesquisas por proporcionar otimização dos processos, o que impulsiona o aprimoramento de técnicas existentes, bem como o desenvolvimento de novas tecnologias que resultem em produtos e soluções mais eficientes.

A partir de estudos dos trocadores de calor, é possível observar que são inúmeros os métodos utilizados para a análise do desempenho dos trocadores de calor, dentre eles destaca-se na literatura o método da média logarítmica das diferenças de temperatura (MLDT), este método por ser de mais fácil utilização na análise de trocadores de calor, é empregado quando as temperaturas de entrada e saída de ambos os fluidos são conhecidas e determina as vazões mássicas, o coeficiente de transferência de calor e a área de transferência de calor do trocador de calor (INCROPERA 2008). Além do método mencionado anteriormente, o método da Efetividade $\varepsilon$-NUT é bastante utilizado e é recomendado para situações em que se queira determinar a taxa de transferência de calor e as temperaturas de saída dos fluidos quente e frio para vazões mássicas dos fluidos e temperaturas de entrada determinada, onde se tenha especificado o tipo de trocador de calor e seu tamanho, ou seja, o que se busca é determinar o desempenho de transferência de calor de determinado trocador de calor ou determinar se o trocador disponível atende as especificações desejadas (S.KAKAÇ 2012).

Entretanto, muitos são os desafios de se acrescentar novas práticas pedagógicas dentro deste contexto, devido às adversidades com relação ao investimento tecnológico nas instituições de ensino superior no Brasil. Consequentemente faz com que professores prefiram lecionar apenas as fundamentações teóricas, porém, especialistas reforçam que as atividades práticas possibilitam o melhor desenvolvimento para compreensão dos conceitos teóricos, impulsionam a capacidade de resolução de problemas e de manipulação dos instrumentos necessário para realização do experimento e sua análise (MELO 2010).

A partir disso, este trabalho contribui com novas perspectivas a serem discutidas em relação ao ensino e evoluem para o melhor entendimento de práticas em relação a trocadores de calor, dentre elas:

- $\quad$ A construção de uma bancada de baixo custo;

- Definição dos objetivos principais de ensino, com o intuito de direcionar a uma inovadora proposta de aprendizado;

- Dar maturidade para o estudante autodesenvolver modelos analíticos e experimentais em um projeto;

Ao passo que é realizado a análise do trocador de calor, COIL, através do dimensionamento do comprimento linear e o número de volutas necessárias para o resfriamento do ar comprimido de um sistema de freio veicular é realizada a comparação do modelo analítico e dados obtidos experimentalmente em convecção natural e forçada construídos em diferentes materiais (aço e cobre) com geometrias distintas e também é definido os volumes de controle entre os segmentos dos tubos nas partes horizontais e 
helicoidais ("coil”).Dessa forma ,garantindo ao aluno profundo aprendizado no tema em questão.

\section{METODOLOGIA DE ENSINO}

A metodologia que será proposta neste trabalho tem como base o método de ensino construtivista, idealizado por Jean Piaget, em que o foco e autor são os alunos, sujeito do processo ensino-aprendizagem, no qual o professor é apenas participante com intuito de mediar à ação do aluno sobre os conteúdos, auxiliando o aluno no processo de construção que faz em relação ao conhecimento (SCHNAID 2003).

O aprendizado é construído de forma gradual a partir de conteúdos assimilados anteriormente. Ao ser aplicado no ensino das matérias de Fenômenos de Transporte ou outras disciplinas que se relacionam, a missão do professor é expor os objetivos principais das aulas aliado a aulas de bancada para que desta maneira possa associar o que é visto com as bibliografias que serão utilizadas no decorrer do curso. Após este ponto, é esperado que os alunos busquem o entendimento do conteúdo e também são reservadas às aulas para que sejam sanadas as dúvidas desenvolvidas no decorrer do processo de aprendizagem.

As aulas que são realizadas na bancada didática têm como objetivo:

- A melhor representatividade do conteúdo teórico;

- Estimular a criatividade, a crítica e o processo de assimilação do conteúdo;

- Demonstrar as ferramentas para a realização de análises e estratégias de solução de problemas;

\subsection{Desenvolvimento experimental}

Todas as análises foram realizadas nas instalações do Laboratório de Motores, Hidráulica e Pneumática, da Faculdade de Tecnologia - Universidade do Estado do Rio de Janeiro (FAT-UERJ). Este experimento foi conduzido em chassi veicular de caminhão funcional, cujas configurações de montagem do trocador de calor puderam ser adaptadas para diferentes geometrias e materiais de um trocador de calor do tipo "coil", conforme apresentados na Figura 1 e Figura 2, com seus respectivos volumes de controle. 


\section{COBENGE de Educação em Engenharia 28 a 30 de SETEMBRO \\ - Evento Online \\ "Formaçāo em Engenharia: Tecnologia, Inovaçâo e Sustentabilidade"'}

Figura 1 - Representação do trocador de calor em cobre com os volumes de controle linear (linha contínua) e volume de controle do "coil"(linha tracejada)

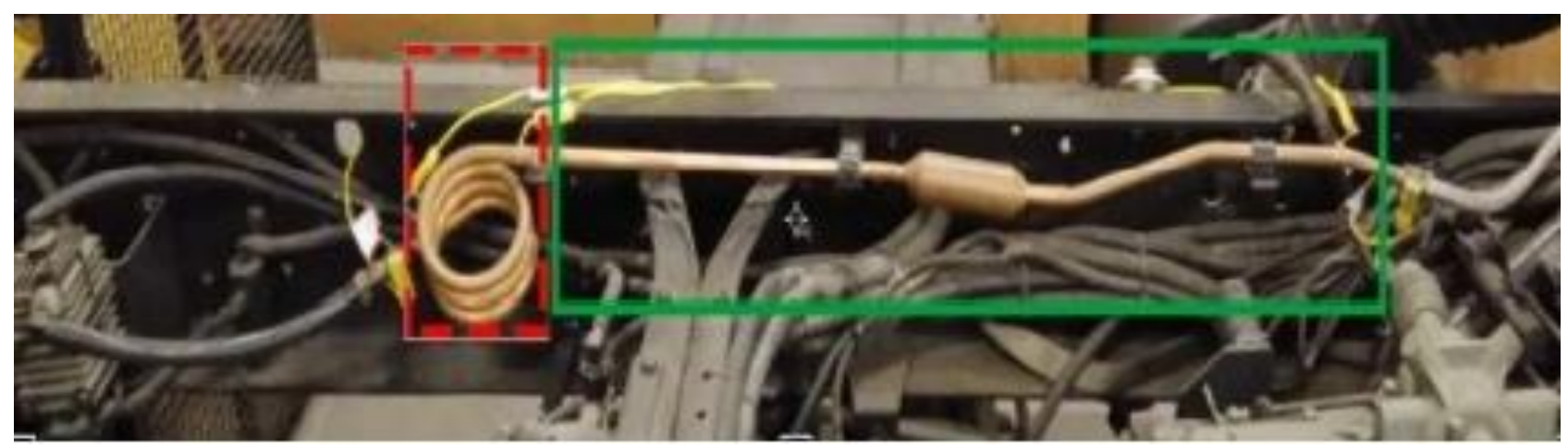

(Fonte: Elaborado pelo autor).

Figura 2 - Representação do trocador de calor em aço com os volumes de controle linear (linha contínua) e volume de controle do "coil" (linha tracejada).

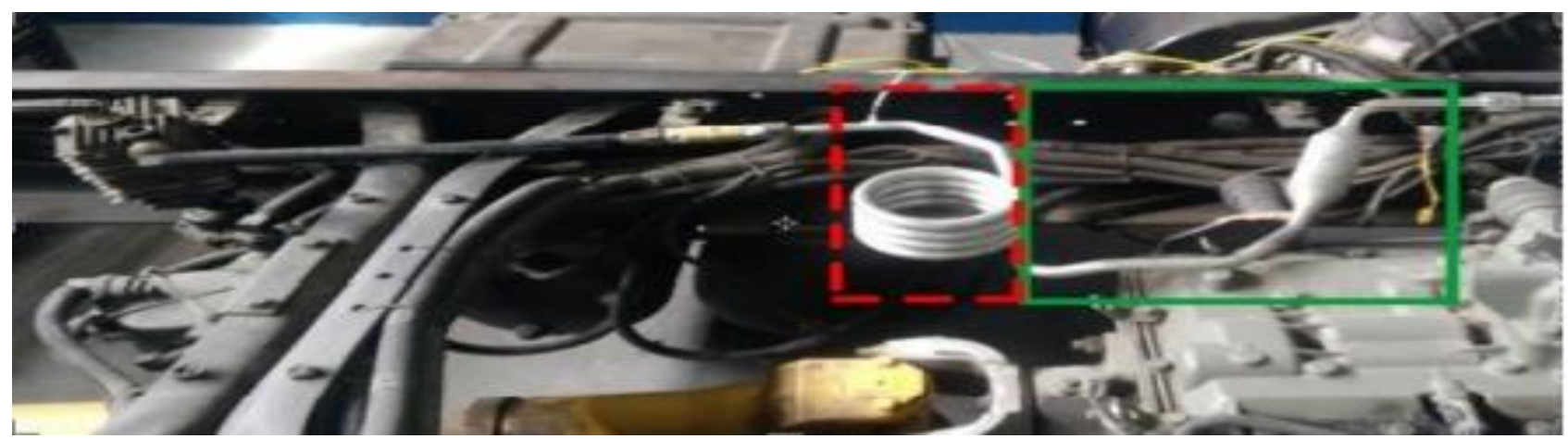

(Fonte: Elaborado pelo autor).

Os trocadores de calor apresentados possuem diferenças em relação ao tipo de material, número de volutas, comprimento linear e no afastamento entre as volutas. Logo em seguida, para realização e análise dos experimentos, foi estabelecida rotação padrão de trabalho do motor em 1500 RPM, faixa de trabalho recomendada pelo fabricante do motor ao usuário do veículo e somado a isso, foi realizado a correta manutenção dos filtros, óleo do motor e uso de óleo Diesel S10 aditivado.

Para todas as condições de volume de controle foi considerado o ar para o fluxo interno e externo, sendo gás perfeito. Desta forma, problemas como contaminação do ar com água e óleo, fatores de incrustação na tubulação não são considerados na análise.

Ao analisar em convecção forçada foi simulado o escoamento de vento através de ventilador centrífugo, vide Figura 3 . No qual foi adaptado para atender as velocidades pré-definidas para análise dos métodos da média logarítmica das diferenças de temperatura (MLDT) e $\varepsilon$-NUT. 
Figura 3 - Ventilador Centrífugo para a realização das condições simuladas sob convecção forçada.

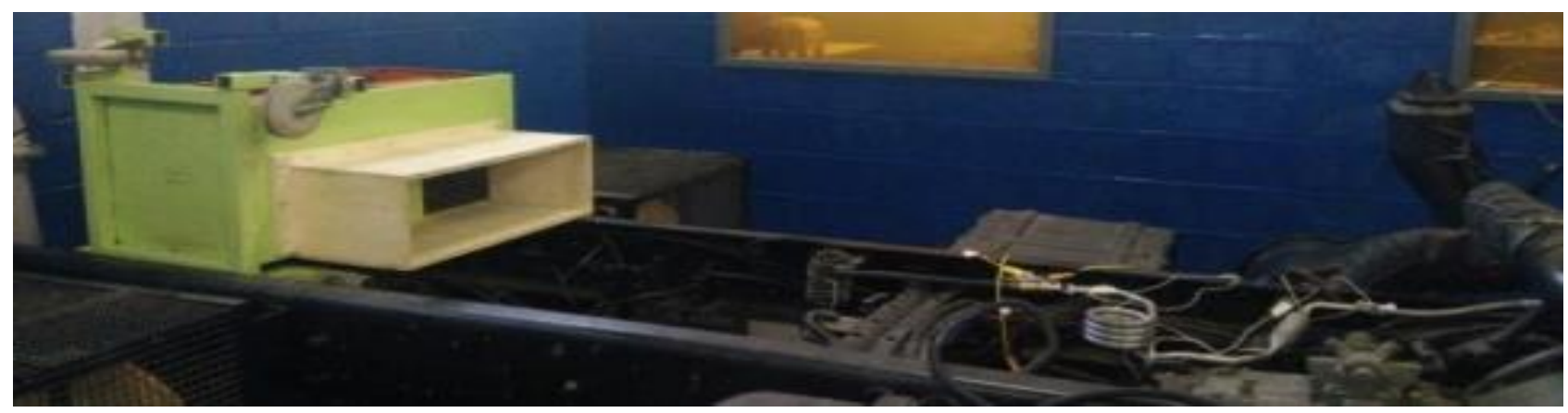

(Fonte: Elaborado pelo autor).

Para medir a temperatura nos escoamentos interno e externo, foram utilizados termopares tipo $\mathrm{K}$ tanto no trocador de calor de aço quanto para o de cobre. Os termopares foram instrumentados no interior das tubulações e próximos a superfície da parede externa de calor, conforme demonstrado na Figura 4.

Figura 4 - Trocador de calor com os seguintes pontos de instrumentação: 1-Temperatura do fluido da parte externa; 2-Temperatura do Fluido Quente de Entrada(Tq,e);3-Temperatura do Fluido Quente Antes do Coil;4-Temperatura do Fluído Quente de Saída (Tq,s) e 5-Temperatura do Fluído parte externa.

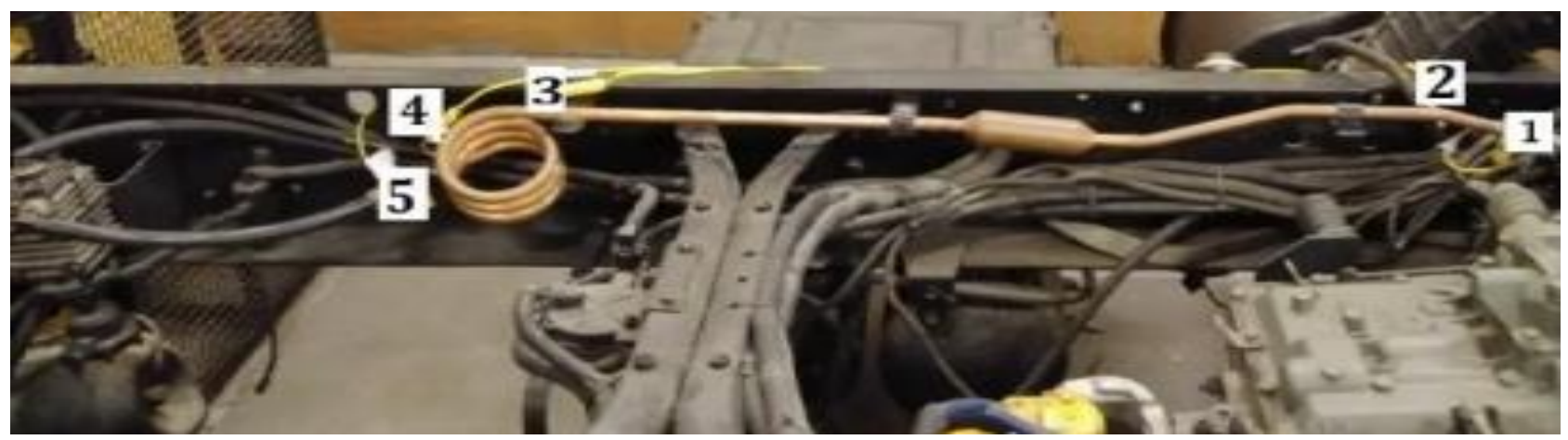

(Fonte: Elaborado pelo autor).

Por fim, a aquisição e monitoramento de dados da temperatura foi realizada através da placa de aquisição de dados modelo Lynx AqDados, configurada de acordo com o relatório de calibração de fábrica e parametrizada em conformidade com o recomendado pelo fabricante para aquisição de temperatura.

\subsection{Equações que regem a análise}

O modelo de estudo foi desenvolvido referente a dois volumes de controle em cada elemento. Isto se deve em função das diferentes formas geométricas que constitui o trocador de calor, sendo uma parte reta e a outra uma parte com volutas. Quanto ao regime de escoamento do fluxo de ar foi considerado regime permanente. Para o desenvolvimento da análise, dois modelos analíticos foram considerados, sendo um modelo para a convecção natural e outro modelo para grande quantidade de fluxo de ar externo, onde foram considerados os métodos de MLDT e $\varepsilon$-Nut.

Para a realização da determinação das variáveis da convecção natural e mista, é calculado a conforme a Equação 1. 


$$
T_{f}=\frac{T_{\infty}+T_{S}}{2}
$$

Onde," $T_{f}$ " é a temperatura de película, " $T_{\infty}$ " é a temperatura ambiente e " $T_{s}$ " a temperatura da parede do trocador de calor.

O coeficiente de transferência de calor $(h)$ é conforme apresentado pela Equação 3 (HOLMAN 1983).

$$
\begin{gathered}
N u=C \cdot(G f \cdot P r)^{m} \\
\boldsymbol{h}=\frac{N u \cdot k}{D}
\end{gathered}
$$

Sendo "Nu" número de Nusselt, "C" constante, " $m$ " constante, "Gf" Grashof, "Pr" Prandtl, " $h$ " coeficiente de transferência de calor e " $D$ " diâmetro do trocador de calor

Para o cálculo da convecção forçada externa para tubos concêntricos em contracorrente, são estabelecidos os métodos de MLDT e $\varepsilon$-NUT conforme demonstrado na Equação 4 (INCROPERA 2008) e através do cálculo do comprimento linear $(L)$ é possível estabelecer o comprimento necessário para o trocador de calor, Equação 5.

$$
\begin{gathered}
\Delta T m l=\frac{\left(T_{q, s}-T_{f, e}\right)-\left(T_{q, e}-T_{f, s}\right)}{\ln \left(\frac{T_{q, s}-T_{f, e}}{T_{q, e}-T_{f, s}}\right)} \\
L=\frac{q}{\left(U \cdot 2 \cdot \pi \cdot r e \cdot \Delta T_{m l} L\right)}
\end{gathered}
$$

Onde " $\Delta T$ ml" é a média logarítmica diferença de temperatura, " $T_{q, e}$ " a temperaturas do fluido quente de entrada, " $T_{f, e}$ " a temperatura do fluído frio de entrada, " $T_{q, s}$ " a temperatura do fluído quente de saída, " $T_{f, s}$ " a temperatura do fluído frio de saída, "re" o raio externo, "q" o calor rejeitado, "L" o comprimento linear e "U" o coeficiente global de transferência de calor

A efetividade é estabelecida por:

$$
\varepsilon=\frac{q}{q_{\max }}
$$

Onde " $q$ " é o calor real do trocador de calor, " $q_{\max }$ " é a taxa de transferência de calor máxima e " $\varepsilon$ " é a efetividade.

O cálculo do calor rejeitado é realizado conforme demonstrado pela Equação 7 e 0 calor rejeitado real é obtido pela Equação 8. 


$$
\begin{gathered}
q_{\text {máx }}=C_{\min } \cdot\left(T_{q, e}-T_{f, e}\right) \\
q=\dot{m} \cdot c_{p} \cdot T_{m}
\end{gathered}
$$

Assumindo, " $C_{\min }$ " como a capacidade térmica mínima, " $\dot{m}$ " a vazão mássica, " $c_{p}$ " 0 calor específico a pressão constante do fluido, " $T_{m}$ " a temperatura de mistura, " $T_{q, e}$ " a temperaturas do fluido quente de entrada e " $T_{f, e}$ " a temperatura do fluído frio de entrada.

A efetividade de um trocador de calor pode ser expressa em função do Nut (número de unidades térmicas), Equação 9.

$$
\begin{gathered}
N u t=\frac{U \cdot A}{C_{\text {min }}} \\
\varepsilon=f\left(N u t, \frac{C_{\text {min }}}{C_{\text {máx }}}\right)
\end{gathered}
$$

Sendo "Nut" o número de unidades térmicas, "U" o coeficiente global de transferência de calor, "A" a area de troca térmica, " $C_{\min }$ " a capacidade térmica mínima, " $C_{\max }=$ " a capacidade térmica máxima e a " $\varepsilon$ " a efetividade.

De acordo com equações apresentadas acima, é possível determinar a formulação específica para os principais tipos e arranjos de trocadores de calor, como pode ser conferido em (INCROPERA 2008) e (S.KAKAÇ 2012).

E para finalizar, o cálculo do número de volutas $(M$ pode ser obtido pela Equação 11 e pela equação 12, pode-se calcular a altura total do coil (K. PATIL 1982).

$$
N=\frac{A}{\pi \cdot D e \cdot \sqrt{(\pi \cdot D h)^{2}+(1,25 \cdot D e)}}
$$

Onde " $N$ " é número de volutas, " $A$ " é área de troca térmica do trocador de calor, " $D e$ " é o diâmetro externo e " $D h$ " é o diâmetro da curvatura.

$\mathrm{Na}$ equação 17, pode-se calcular a altura total do coil em função do valor do número de volutas, a distância de centro a centro do passe entre duas volutas $(p)$ e diâmetro externo, (K. PATIL 1982).

$$
H=(N \cdot p)+D e
$$

Considerando "H" é a altura total do "coil", "N" o número de volutas, " $p$ " o passe entre duas volutas e "De" é o diâmetro externo.

\section{$3 \quad$ RESULTADO E DISCUSSÕES}


O monitoramento das temperaturas nos trocadores de calor, aço e cobre, sob convecção natural e forçada se manteve até o sistema se estabelecer em regime permanente. A Figura 5 demonstra as curvas de temperatura em função do tempo para convecção natural e a Figura 6 para convecção forçada em ambos os trocadores de calor.

Figura 5 - Curvas características dos dados obtidos experimentalmente das temperaturas dos trocadores de calor de aço e do cobre com convecção natural.
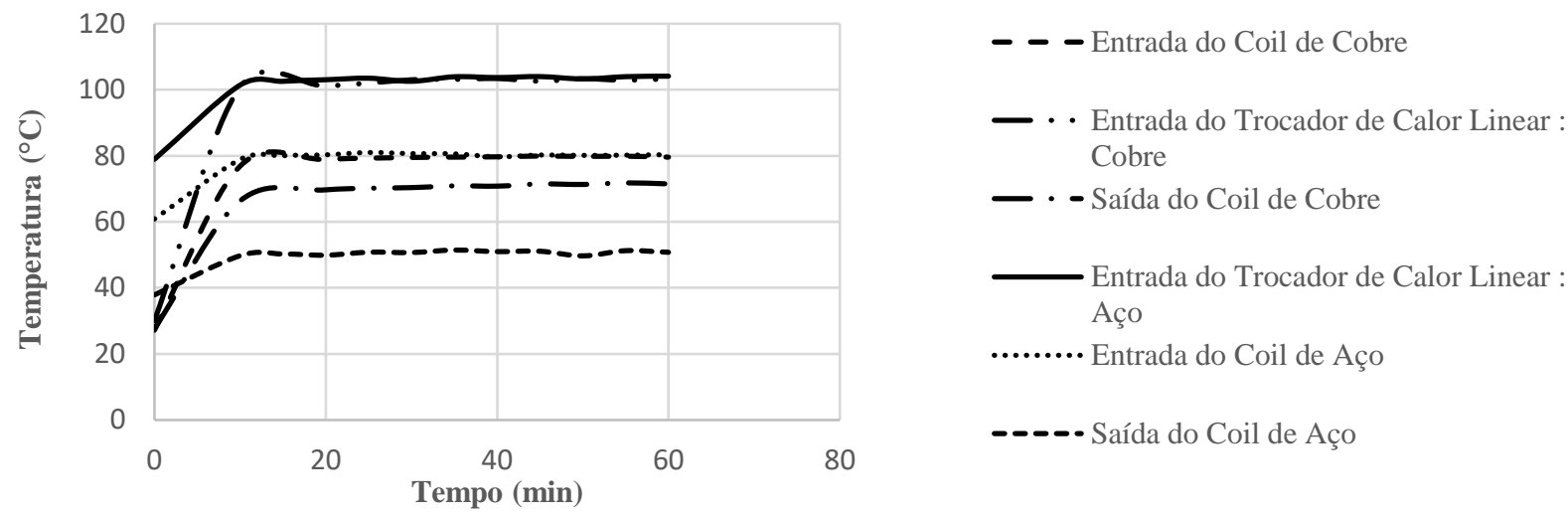

(Fonte: Elaborado pelo autor)

Figura 6 - Curvas características dos dados obtidos experimentalmente das temperaturas dos trocadores de calor de aço e do cobre com convecção forçada.

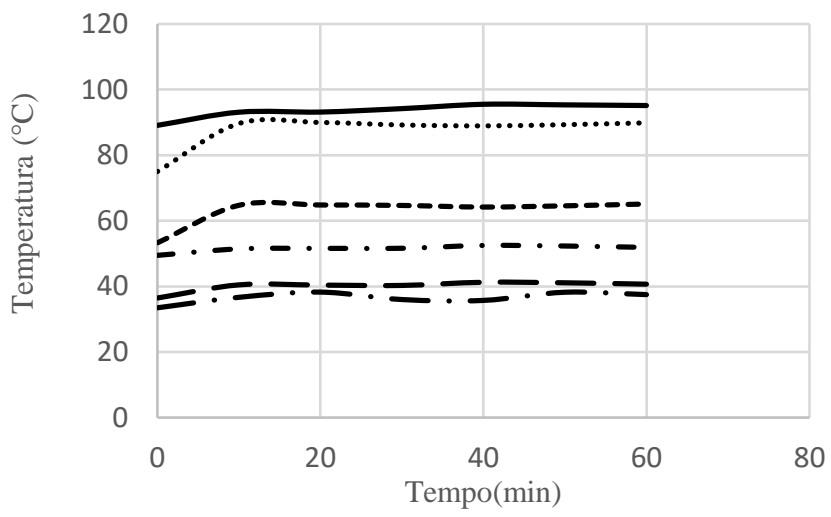

- - Entrada do Coil de Cobre

—— Entrada do Trocador de Calor Linear: Cobre

— - Saída do Coil de Cobre

........ Entrada do Trocador de Calor Linear: Aço

-- - Entrada do Coil de Aço

- - Saída do Coil de Aço

(Fonte: Elaborado pelo autor).

Para a convecção forçada externa, obteve-se a verificação das velocidades de escoamento do vento nos pontos de medição de entrada e saída para ambos os volumes de controle. Como forma de melhor trabalhar com as variações das velocidades em função das variações geométricas dos componentes, foi estabelecido à média das velocidades nestes pontos para as análises teóricas. As velocidades médias do escoamento externo podem ser verificadas pelo Quadro 1.

Quadro 1 - Velocidade média de escoamento externo com convecção forçada nos volumes de controle linear e do coil para cobre e aço.

\begin{tabular}{|c|c|}
\hline \multicolumn{2}{|c|}{ Velocidade Média do Escoamento Externo (m/s) } \\
\hline Trocador de calor: Cobre & 0,03 \\
\hline Trocador de calor: Aço & 0,52 \\
\hline
\end{tabular}

(Fonte: Elaborado pelo autor) 
Os trocadores de calor na convecção forçada são tipicamente classificados em função da configuração do escoamento e do tipo de construção (INCROPERA 2008). Durante a montagem do experimento, foi observado ser mais favorável à montagem dos trocadores de calor no chassi do veículo e a posição do ventilador centrifugo para um arranjo em contracorrente, ou seja, os fluidos quente e frio entram no sistema por extremidades opostas, escoam em sentidos opostos e deixam o sistema por extremidades opostas. Esta afirmação pode ser constatada pela Figura 8 para trocador de calor de cobre e pela Figura 9 para o trocador de calor de aço, ambos para o primeiro e o segundo volume de controle, pois demonstra as distribuições de temperaturas nos fluidos quente e frio associadas a um trocador de calor com escoamento em contracorrente.

Figura 8 - Distribuição de temperatura nos trocadores de calor de cobre, com escoamento dos fluidos em contracorrente no primeiro e segundo volume de controle.
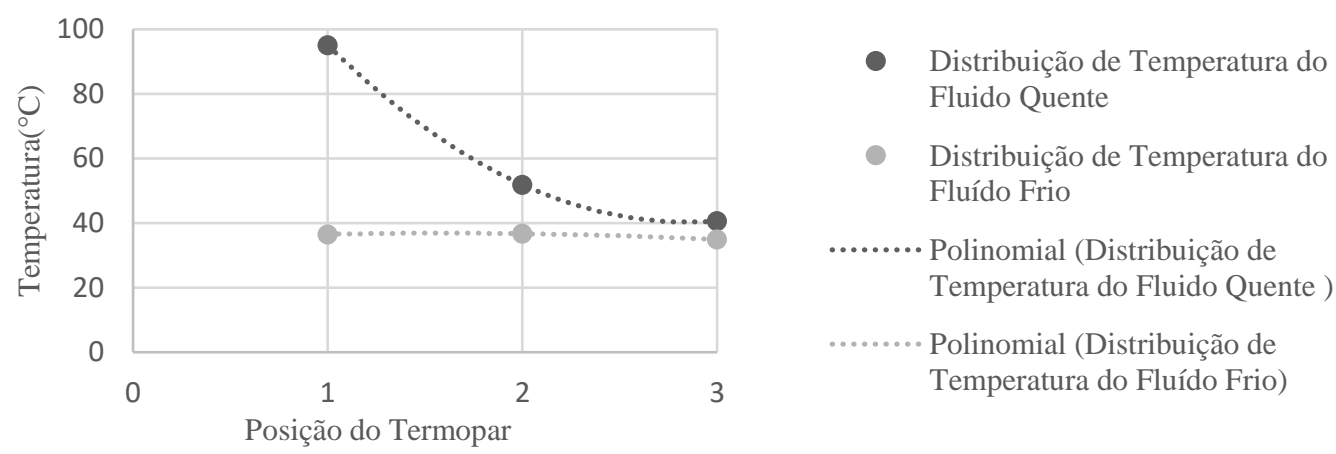

(Fonte: Elaborado pelo autor)

Figura 9 - Distribuição de temperatura nos trocadores de calor de cobre, com escoamento dos fluidos em contracorrente no primeiro e segundo volume de controle.

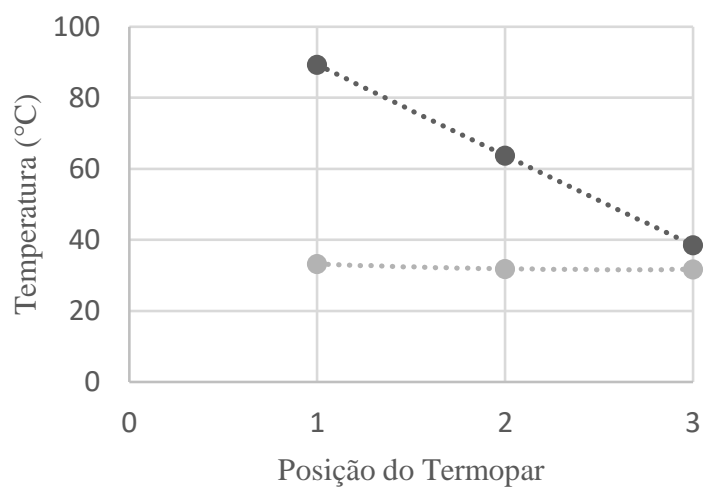

- Distribuição de Temperatura do Fluído Quente

- Distribuição de Temperatura Fluído Frio

Polinomial (Distribuição de Temperatura do Fluído Quente )

Polinomial (Distribuição de Temperatura Fluído Frio )

(Fonte: Elaborado pelo autor)

Inicialmente, a configuração do escoamento em contracorrente proporciona a transferência de calor entre as parcelas mais quentes dos dois fluidos em uma extremidade, enquanto na outra ocorre a transferência de calor entre as parcelas mais frias dos dois fluidos. É importante notar que a temperatura de saída do fluido frio pode, nesse caso, ser superior a temperatura de saída do fluido quente.

Os índices subscritos 1 e 3 são usados para designar as extremidades opostas do trocador de calor. Essa convenção é utilizada em todos os tipos de trocadores de calor aqui analisados. Para o escoamento em contracorrente, tem-se que subscrito 1 corresponde a 
temperatura do fluido quente de entrada e frio de saída e o subscrito 3 está relacionado as temperaturas do fluido quente de saída e frio de entrada, (INCROPERA 2008).

Para as análises da convecção natural, buscou-se encontrar em função dos volumes de controle linear e do "coil", o comprimento linear do trocador de calor do cobre e do aço. Essas análises são demonstradas graficamente pela Figura 10.

Figura 10 - Histograma dos resultados das análises da convecção natural, comprimento linear para cada volume de controle dos trocadores de calor de cobre e aço, respectivamente.

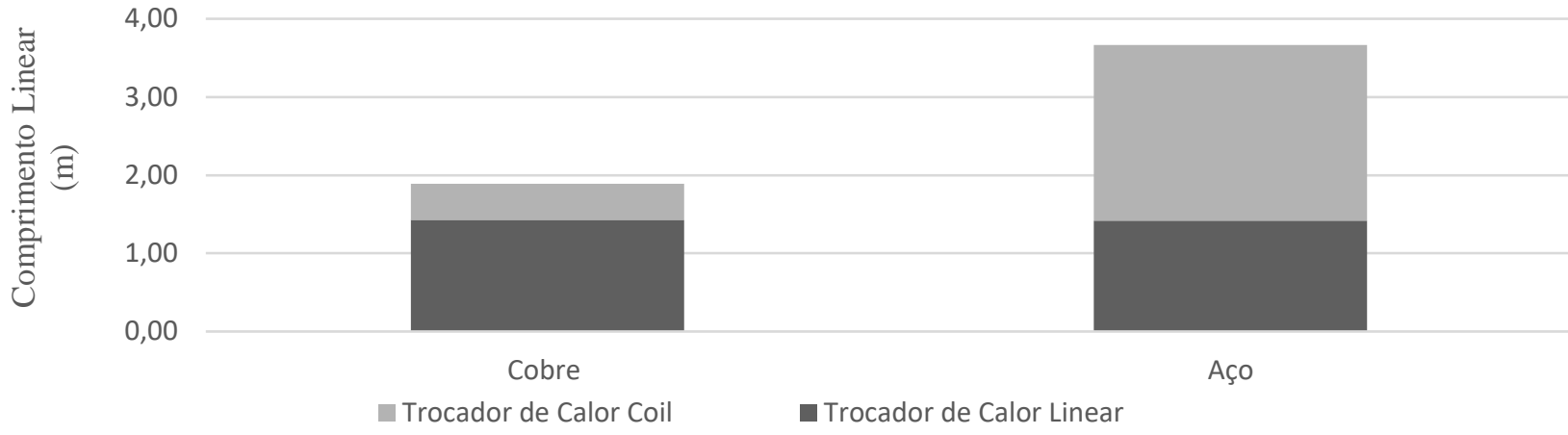

(Fonte: Elaborado pelo autor)

Os valores encontrados na convecção natural externa são equivalentes para os dois volumes de controle. O calor rejeitado é dependente da área de troca térmica e das geometrias do trocador de calor, com isso observou-se a partir das análises realizadas que a tubulação linear de cobre e de aço possui uma diferença de área de troca térmica de acordo com o calor rejeitado para cada trocador de calor. Dessa forma, obteve-se uma variação média de 50,92\% do comprimento linear para o trocador de calor de aço e 18,64\% para o trocador de calor de cobre, comparando com as suas respectivas dimensões lineares reais.

As análises para os volumes de controle linear e do "coil" na convecção forçada externa em uma vazão mássica constante em contracorrente, consegue-se aplicar os modelos analíticos dos métodos da média logarítmica das diferenças de temperaturas (MLDT) e da efetividade $\varepsilon$-Nut. Com isso, foi gerado em função dos volumes de controle e do tipo de materiais o comprimento linear do trocador de calor. Conforme demonstrado graficamente pela Figura 11.

Figura 11 - Histograma dos resultados das análises da convecção forçada para os métodos E-Nut e DTML, comprimento linear para cada volume de controle dos trocadores de calor de cobre e aço, respectivamente.

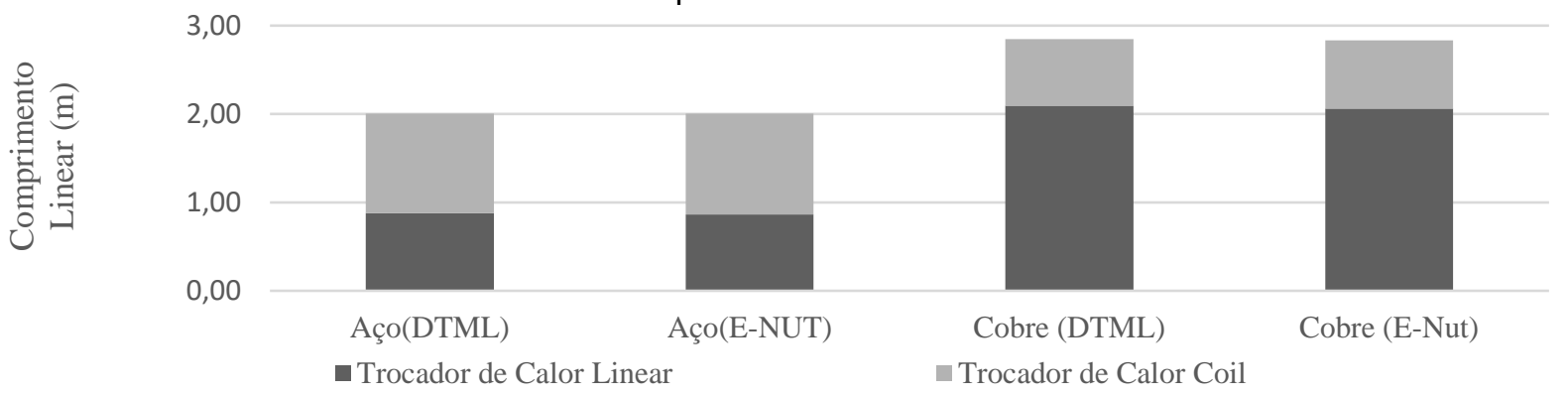

(Fonte: Elaborado pelo autor)

Os resultados dos métodos propostos foram importantes para a verificação do dimensionamento do trocador de calor com escoamento em contracorrente. Como demonstrado anteriormente, a diferença de dimensionamento linear entre os dois métodos 
utilizados obteve uma variação de $17,46 \%$ para aço e $22,41 \%$ para o cobre. O calor rejeitado no trocador de calor nestas condições depende da área de troca térmica, as geometrias do trocador de calor e a configuração de montagem no chassi em um veículo comercial.

É importante ressaltar que quanto maior o número de volutas e espaçamento entre elas, a área de troca térmica para convecção forçada será beneficiada. Esta constatação pode ser verificada pelo número de volutas em função dos métodos para convecção forçada DTML e E-Nut, conforme a Figura 12. Verificou-se que o número de volutas em média dos dois métodos proposto variou cerca de $19,21 \%$ para o "coil" de aço e $21,14 \%$ para o "coil" de cobre, comparado com as dimensões reais dos dois "coils", sem considerar o arredondamento para número inteiro superior do cálculo do número de volutas.

Figura 12 - Histograma dos resultados das análises da convecção forçada para os métodos E-Nut e DTML, quantidade do número de volutas dos trocadores de calor de cobre e aço, respectivamente.

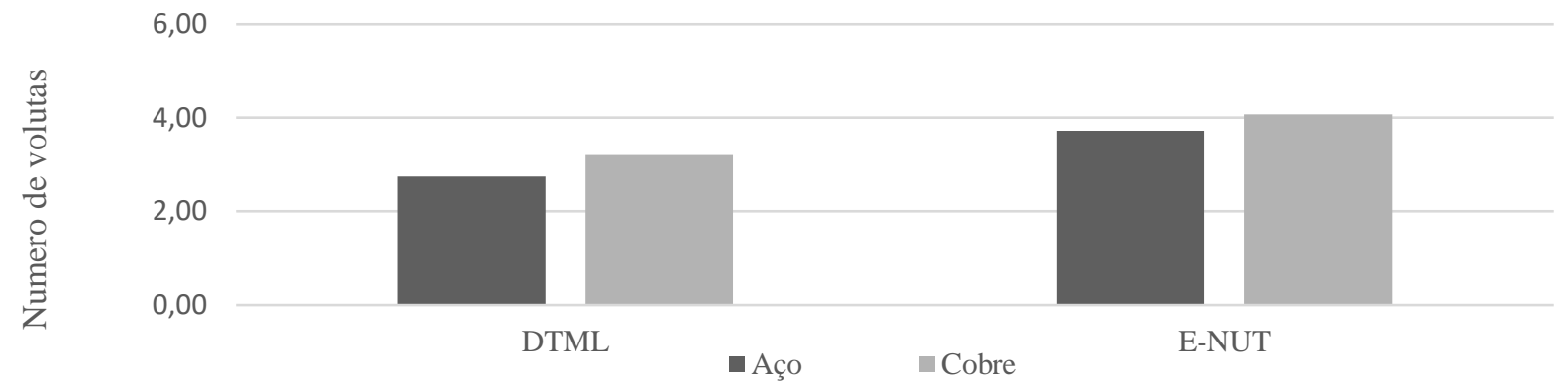

(Fonte: Elaborado pelo autor)

\section{CONCLUSÃO}

É possível concluir que a eficiência do trocador de calor é influenciada predominantemente pela área de troca térmica, material de fabricação dos tubos, convecções externas e internas. Demais, os resultados foram em função do ar, considerado neste estudo como fluido ideal, desconsiderando efeitos de contaminação por impurezas, como a água (devido a humidade do ar) e óleo (contaminação proveniente do compressor) e ou efeitos de incrustações e perda de carga, que influenciam os resultados teóricos, devido a alteração dos parâmetros considerados.

Os resultados apresentados pela proposta analítica foram satisfatórios, como demonstrados através do cálculo do comprimento linear e a quantidade do número de volutas em comparação ao modelo experimental utilizado em aplicação real pela montadora. Sob as condições impostas de convecção forçada e natural o modelo foi analisado por uma média aritmética dos três métodos propostos para a definição do comprimento linear e o número de volutas, o que resultou em uma variação em média de $5,33 \%$ da dimensão real para o trocador de calor em cobre e $8,73 \%$ para o trocador de calor em aço. Desta forma, sugere-se que ao dimensionar trocadores de calor, é necessário analisar não apenas um único método, mas todas as condições possíveis para melhor caracterizar o modelo.

Para trabalhos futuros, o conteúdo deste estudo mostrou ser uma eficiente ferramenta para otimização do conceito e desenvolvimento de um novo modelo com geometrias diferenciadas e trabalhando em condições de contracorrente mais severas, com a possibilidade de grande variação mássica externa, simulando o veículo no estado dinâmico em diferentes velocidades, podendo mesmo favorecer a redução de custo, através da otimização proposta. 


\title{
$5 \quad$ AGRADECIMENTOS
}

Ao Laboratório de Motores, Hidráulica e Pneumática da Universidade do Estado do Rio de Janeiro, (Campus Resende), companheiros e técnicos. Este trabalho foi desenvolvido e montado graças aos esforços e compreensão do professor (orientador) Luiz Cordeiro.

\section{REFERÊNCIAS}

\section{Livros:}

Holman, J.P., 1983." Transferência de Calor”, McGraw-Hill Ltda, São Paulo, Brasil

Incropera, F.P. [et al.], De Witt, D. P., Bergman, T.L., Lavine, A.S., 2008. "Fundamentos de Transferência de Calor e de Massa", Ed. LTC, 6 edition., Rio de Janeiro, Brasil.

S.Kakaç,Liu.H,APramuanjaroenkij,2012."Heat

Exchanges,Selection,Rating,and Thermal Design",third Edition.

\section{Artigos de periódicos:}

K. Patil, Ramachandra Shende, B.W. and Ghosh, Prasanta.,1982. "Designing A Helical-Coil Heat Exchanger”. Chemical Engineering (New York), Vol. 89, pp. 85-88.

SCHNAID, F; TIMM, M. I; ZARO, M. Considerações sobre uso de modelo construtivista no ensino de Engenharia: disciplina de projeto com graduandos e mestrandos. Revista Renote, Porto Alegre, v. 1, n. 1, p. 1-21, 2003.

\section{Monografias, dissertações e teses:}

MELO, Júlio. De Fátimo Rodrigues de. Desenvolvimento de atividades práticas experimentais no ensino de biologia - um estudo de caso. 2010. 75 f . Dissertação de Mestrado, Universidade de Brasília, Brasília, 2010.

\section{DIDATIC PROCEDURE FOR SIZING COIL COMPACT HEAT EXCHANGER}

\begin{abstract}
This work aims to perform thermal analysis in a "coil" type heat exchanger, used in a vehicle pneumatic brake system. For this analysis, thermal mapping was developed through vehicular simulation in static and dynamic conditions within the premises of the Mechanical Laboratory / UERJ / Campos Regional de Resende. The result of this work served to assist in the understanding of the dimensioning, the application of this heat exchanger and the influence of geometric effects in its construction for thermal exchange culminating in the development of experimental classes in the discipline of Experimental Transport Phenomena for the mechanical engineering course through the creation of a low cost bench in order to provide students with innovation in the pedagogical proposals of the subject and other related subjects.
\end{abstract}

Keywords: coil type heat exchanger, designer coil, vehicle brake system and didactic bench. 